\title{
The Effect of Specimen Dimension on Residual Stress Relaxation of the Weldments
}

\author{
Zhongyuan Qian $^{1, a^{*}}$, Scott Chumbley ${ }^{2, b}$, Eric Johnson ${ }^{3, c}$ \\ ${ }^{1}$ Invetech LLC, 10665 Richmond Ave, Suite 192, Houston, TX, USA \\ ${ }^{2} 214$ Wilhelm, lowa State University, Ames, IA, USA \\ ${ }^{3}$ John Deere Technology Center, Moline, IL, USA \\ azqian@invetech.com, bchumbley@iastate.edu, ' JohnsonEricM@johndeere.com \\ *phone: (+1)515-451-6133, fax: (+1)713-781-8235, zyqianisu@gmail.com
}

Keywords: residual stress; finite-element analysis; relaxation; welding; X-ray diffraction.

\begin{abstract}
The purpose of this study is to evaluate the residual stress relaxation behavior in weldments. The stress relaxation is studied while successively reducing the size of weld specimens. Finite-element modeling was used to simulate the stress relaxation, and then an empirical model was derived based on the experimental and modeling results. The results of this study shall encourage industry users to utilize more plentiful conventional X-ray diffractometers for residual stress measurement of large weld components.
\end{abstract}

\section{Introduction}

The failure of a mechanical component is often a combination of external loading, the manner in which the load was applied, and the stress state present in the sample as a result of manufacture or assembly. The most common method of failure in manufactured parts subjected to cyclic loading is fatigue. [1] The residual stresses that develop in a part during manufacture or use are one of the most influential factors in determining the fatigue resistance of welded components. [2-5] Common manufacturing methods, e.g. welding, machining, hardening, casting and forging, can all produce residual stresses in the final product. [6-8] Thus, good knowledge of the residual stress profile will lead to more accurate fatigue life prediction [9] and allow the optimization of the welding process parameters.

Diffraction techniques are one of the most reliable and effective methods to measure residual stress. Neutron and synchrotron diffraction have the ability to measure the stress in bulk samples [10, 11], however the resources are quite limited and the test costs can be very high, which discourages many industry users from using these methods for tracking residual stress in manufactured parts. Consequently a conventional X-ray diffractometer is often used. Nevertheless, due to the sample size limitation of most laboratory instruments, many of the specimens need to be cut in order to fit into the typical sample holder or test fixture. Stress relaxation and redistribution is expected when reducing the size of samples. [4] In recent decades numerical simulation have been widely employed and proven to be powerful tools to facilitate residual stress measurement and the study of part performance as related to residual stress. [12-17] 
The purpose of this study is to develop a numerical model for predicting the amount of residual stress relaxation during cutting of weldments. The experiments were carried out on ASTM A572 ( $g r a d 50$ ) weldments to measure the actual residual stress using the X-ray diffraction technique. A finite-element model was used to verify the relaxation behavior of a typical residual stress field during consecutive cutting. A heat tint zone (HTZ) is always visible on the surface adjacent to the T-weld and on the backside. Heat tint indicates that the base metal has reached a temperature at which the progressive thickening of the surface oxide layer happens, and the colors formed on the surface indicate the temperature to which the steel has been heated [18]. Measurement of residual stresses (caused by expansion and contraction due to the non-uniform heating and cooling that occurs during welding) as determined using X-ray diffraction is related to strain produced in the lattice on an atomic scale. The experimental results obtained in this study were compared with the FE model prediction and an empirical numerical relationship of residual stress relaxation with dimensional reduction was derived.

\section{Experiments and Results}

Specimen and Material The base material of the specimen under study was ASTM A572 (Grade 50) steel with a composition (wt.\%) of $0.23 \mathrm{C}, 1.35 \mathrm{Mn}, 0.4 \mathrm{Si}, 0.01 \mathrm{~V}, 0.04 \mathrm{Nb}$. This high strength low alloy steel finds its best application where there is need for more strength per unit of weight. The specimens were T-welds manufactured using robotic metal-inert-gas (MIG) welding. The plates are $200 \mathrm{~mm} X 1200 \mathrm{~mm}$ large as-received and they were cut into $100 \mathrm{~mm}$ X $100 \mathrm{~mm}$ pieces for the experiments, as shown in Fig. 1. One weld pass was made on each side of the $T$ and each weld bead is $8 \mathrm{~mm}$ wide when measured from the center of the T joint. The size of the HTZ as measured on the backside of the weld was found to have a total width of approximately $45 \mathrm{~mm}$.
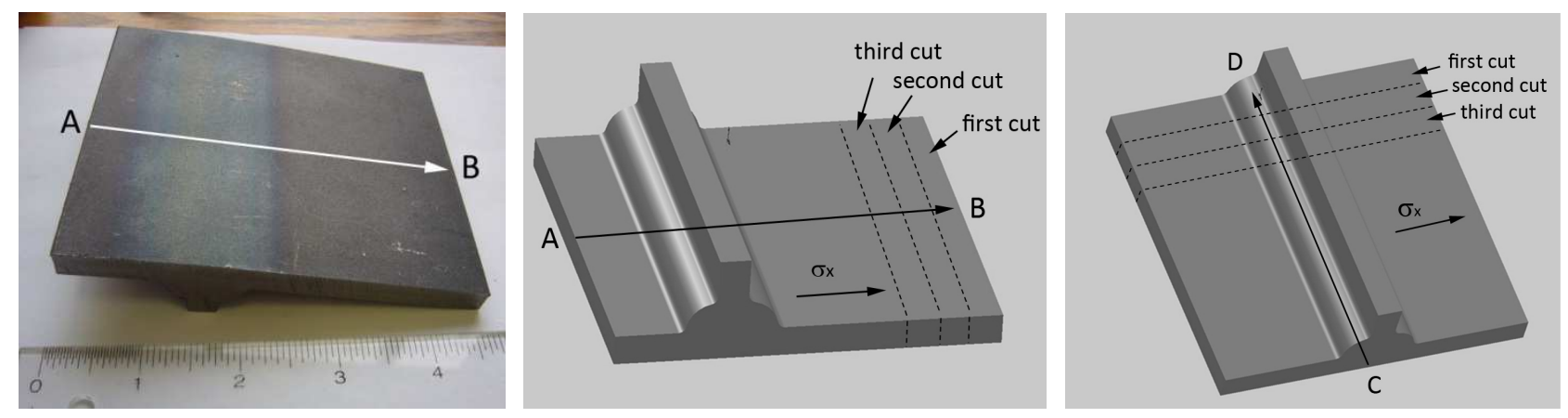

Figure 1. a) Heat tinted zone (HTZ) on the back size of specimen is $45 \mathrm{~mm}$ wide. b) sketch of sample $1 \& 2$, which were sectioned parallel to weld; c) sample $3 \& 4$ sectioned perpendicular across weld.

Samples for this study designated 1 and 2 were offset a bit with $70 \mathrm{~mm}$ on one side and $30 \mathrm{~mm}$ on the other, Fig. 1a. These samples were subsequently sectioned parallel to the weld direction. Samples 3 and 4 (Fig. 1b) were symmetric with $50 \mathrm{~mm}$ on each side of the $\mathrm{T}$ and were sectioned perpendicular to the weld.

X-ray Diffraction Measurement of Residual Stress A Bruker D8 diffractometer equipped with a two-dimensional area detector [19] and $\mathrm{Cr}$ tube was used to acquire the experimental X-ray diffraction data. Young's modulus and Poisson's ratio of the material are $205 \mathrm{GPa}$ and 0.29, respectively. The $(211)$ peak $\left(2 \theta=156^{\circ}\right)$ was examined and each acquisition was obtained using 
$30 \mathrm{kV}, 50 \mathrm{~mA}$, by the $\Psi$ method in accordance with ASTM E915 standard [20]. The residual stresses were measured on the back-side of the specimens [21] due to the ease of accessibility. In this study only the stress in the $x$ direction ( $\sigma_{\mathrm{x}}$, indicated in Fig.1) which is perpendicular to the weld, is of interest because in most cases fatigue cracks open in a direction along the weld toe, which is caused by $\sigma_{\mathrm{x}}$. Residual stresses measured on multiple areas far from the weld showed an average compressive stress of $250 \mathrm{MPa}$; this amount is due to the shot blasting received by the plate during the pre-treatment operation.

The residual stress along path A-B (as shown in Fig.1b) was measured first, and then 10mm of material was carefully removed along the welding direction. Stress along path A-B was then re-measured on the now smaller piece. These procedures were repeated on Samples 1 and 2 to ensure the reproducibility of the experiments. Path C-D was measured in the same manner on Samples 3 and 4 except that the sectioning cuts are made perpendicular to the welding direction, as show in Fig. 1c.

The results of stress measurements across the width of the T-weld for samples 1 are shown in Figure 2. The increase in stress from the two weld passes over the initial compressive stress present in the plate is evident. Since the weld was performed using two passes, one on either side of the T, it is clear that the heat from the second weld pass results in stress relaxation on the first weld, producing a lower peak residual stress. The high residual compressive stress of the original plates (-250MPa) and the stress relaxation of the second weld pass results in a much lower overall stress than what might be expected. Only the second weld passes show a residual tensile stress. The stress distribution of $\sigma_{\mathrm{x}}$ is similar in both the samples.

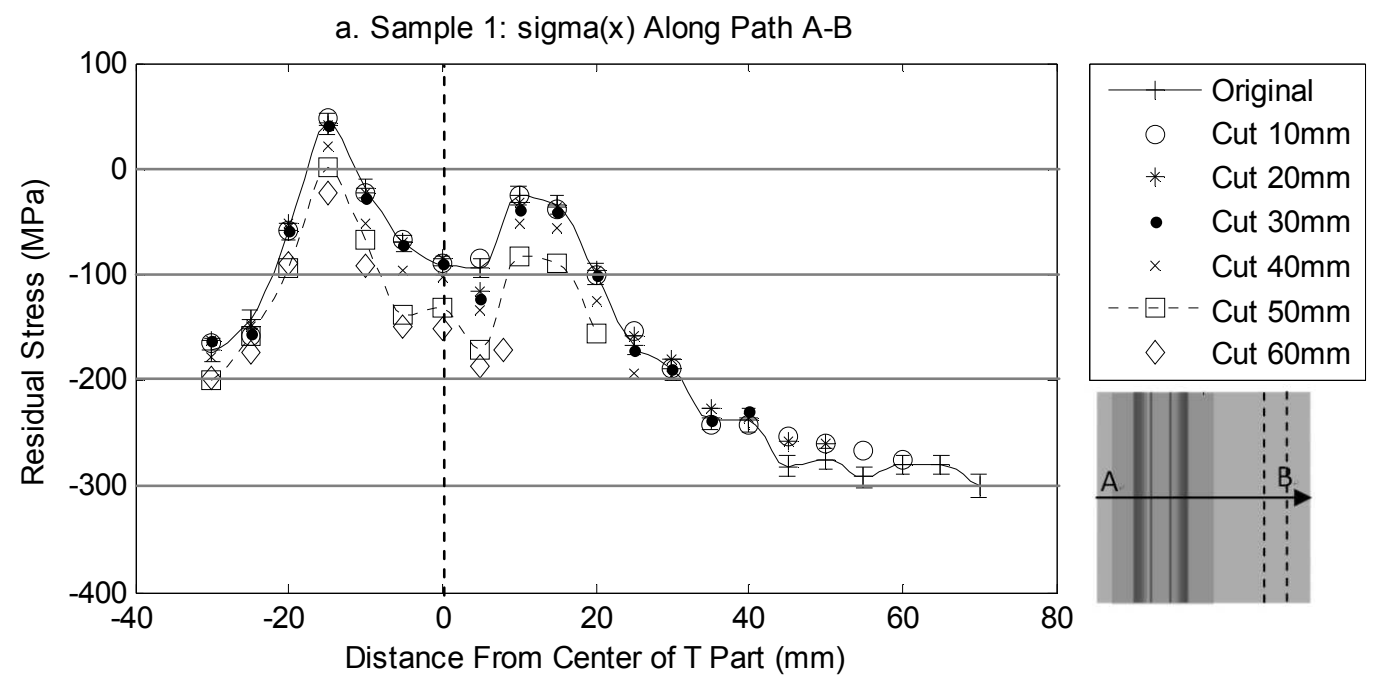

Figure 2. Redistribution of the residual stress $\sigma_{\mathrm{x}}$ along path A-B on sample 1. (Error $< \pm 6 \mathrm{MPa}$ )

As shown in Fig. 3, relaxation of the stress can be seen as sectioning occurs parallel to the weld direction. In this case $\sigma_{\mathrm{x}}$ is seen to change substantially as a function of sectioning, with measurements near the edges of the sample showing the greatest change in value. 


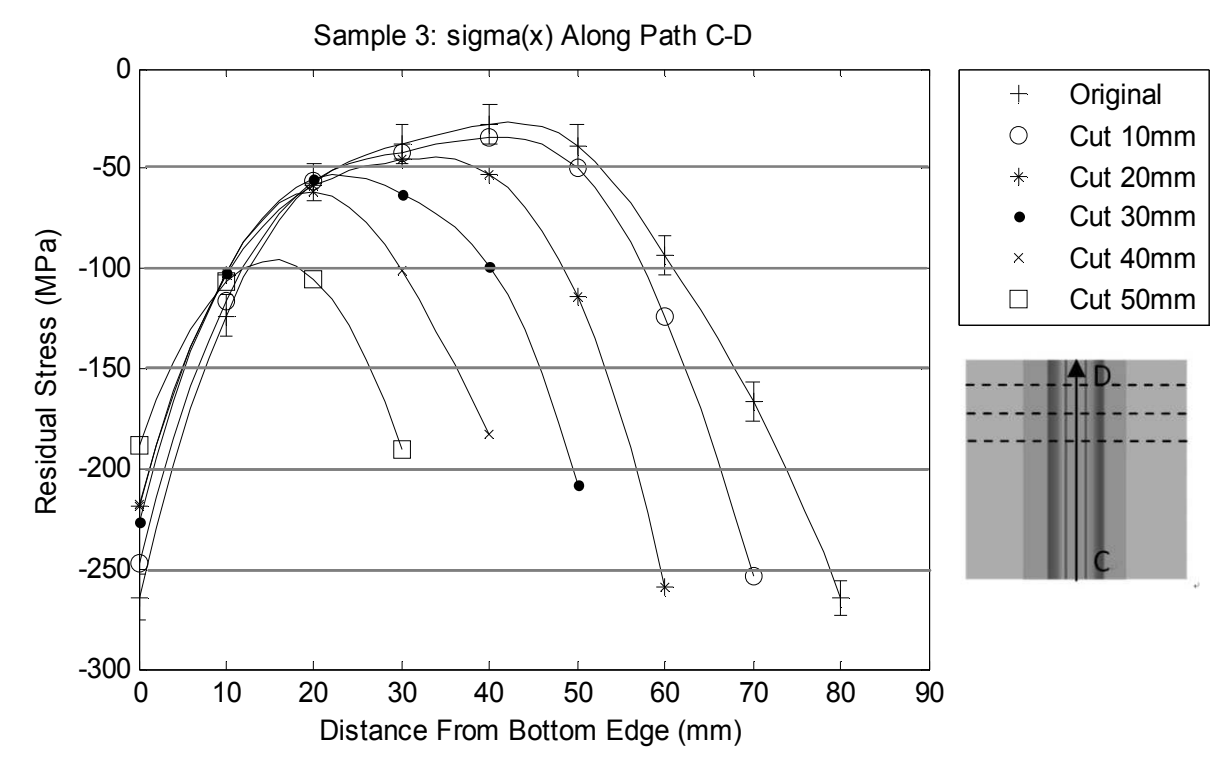

Figure 3. Redistribution of the residual stress $\sigma_{\mathrm{x}}$ along C-D on sample 3 .

Numerical Predictions The ANSYS commercial finite-element software [22] was used for the modeling. Due to the symmetry only half of the plate was simulated, showing the stress from the middle of the $\mathrm{T}$ weld through the base metal to the edge. A two-dimensional plate model was built using a 100X100 mesh of 8-noded, thermal-structural coupled, plane stress elements (element 183 and 77). A typical residual stress field, with tension in the weld and compression in the base material, was initialized by applying a thermal load on the left side and manipulating the thermal expansion coefficient of the elements. One FE step was then taken, giving the stress distribution for the initial stress equilibrium state, and the resultant values along paths A-B and C-D were normalized to give a peak value of unity. Subsequent analysis steps were run where elements were sequentially removed to simulate cutting the material. A summary of the results is shown in Fig. 4. As regarding the data nomenclature, cut $1 / 10$ stands for removal of one tenth $(10 \mathrm{~mm})$ of the material along the direction A-B, 2/10 stands for two tenths $(20 \mathrm{~mm})$, etc. The stress was also simulated along direction $\mathrm{C}-\mathrm{D}$, where in this case the cuts were made perpendicular to the weld direction.
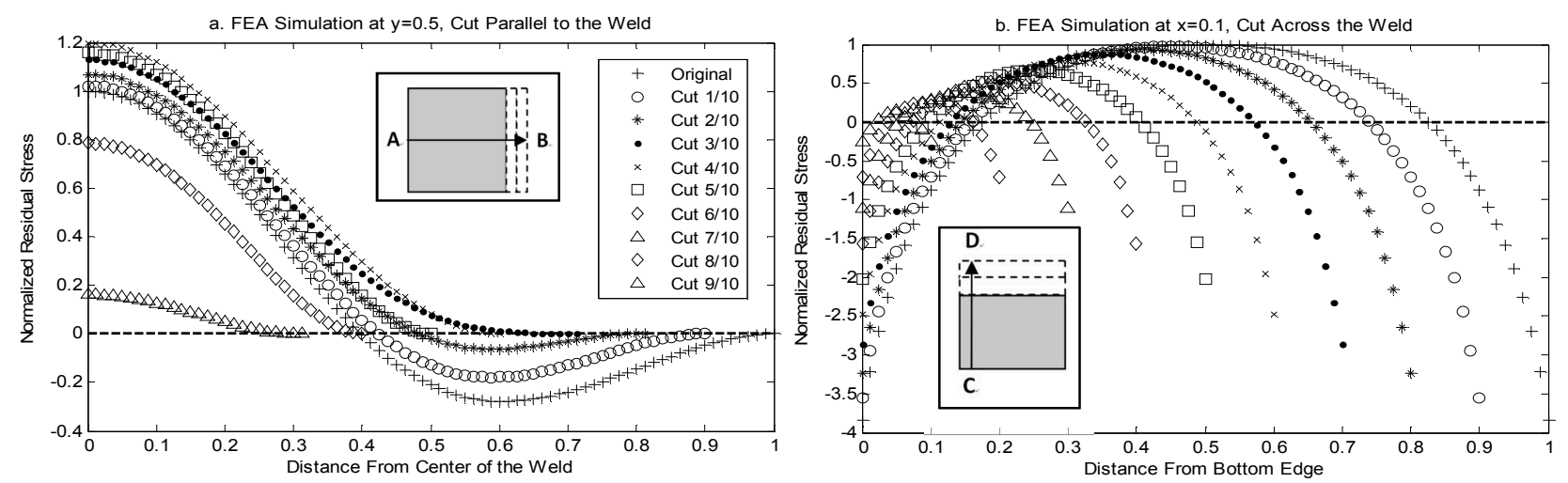

Figure 4. Relaxation of $\sigma_{\mathrm{x}}$ in the finite-element model. (a) path A-B after consecutive cuts parallel to the welding direction; (b) path C-D after consecutive cuts perpendicular to the y axis. 


\section{Discussion}

The simulated stress redistribution along path A-B (Fig. 4a) predicts the stress changes over a fairly narrow range until the dimensions are within the length of the heat affected zone $(x=0.4$ for the FE model). When considering the actual measured stress values along path A-B a very slight increase or decreases occurs initially with removal of material until the cuts near the heat tint zone. In Fig. 2, when within $10 \mathrm{~mm}$ of the HTZ, a slight decrease in stress is seen (40 mm cut). This decrease becomes much more apparent when the sample is sectioned at the edge of the HTZ (50 mm cut). In general, the following observations can be made for both simulation and actual measurements: (1) there is only a minor change of residual stress when the cut is outside the HTZ; (2) relaxation of stress only becomes significant after the cut reaches the HTZ. The relaxation of the highest stress (R) is defined as [9],

$$
R=\frac{\sigma_{\max }-\sigma}{\sigma_{\max }-\sigma_{0}} * 100 \%
$$

where $\sigma_{\max }$ is the highest residual stress on the original size of the specimen, $\sigma$ is the highest residual stress on the current size of the specimen, $\sigma_{0}$ is the equilibrium stress of $-250 \mathrm{MPa}$ due to initial shot peening process. This stress relaxation is plotted as a function of ratio $t=D / a$ in Fig. 5a, where $a$ is the size of Heat Tinted Zone (HTZ) and $D$ is the distance from the specimen edge to the HTZ boundary. In either samples measured residual stress drops slowly, only becoming greater than $10 \%$ when the material is sectioned such that the ratio $t$ is less than 0.3 , which means the cut is very close to the HTZ. Little or no stress relaxation is observed when $t$ is greater than 0.5 . Note that the negative value of ratio $t$ occurs due to sectioning of the weld within the HTZ.

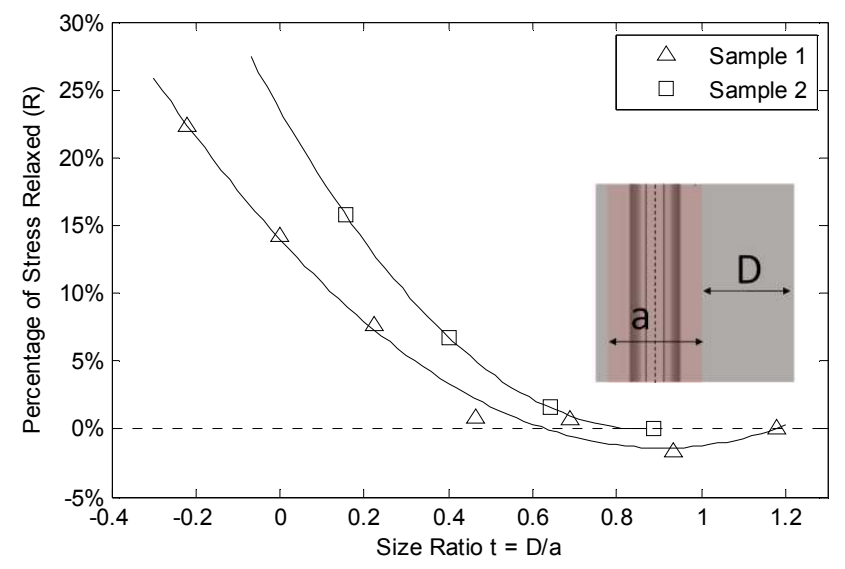

(a)

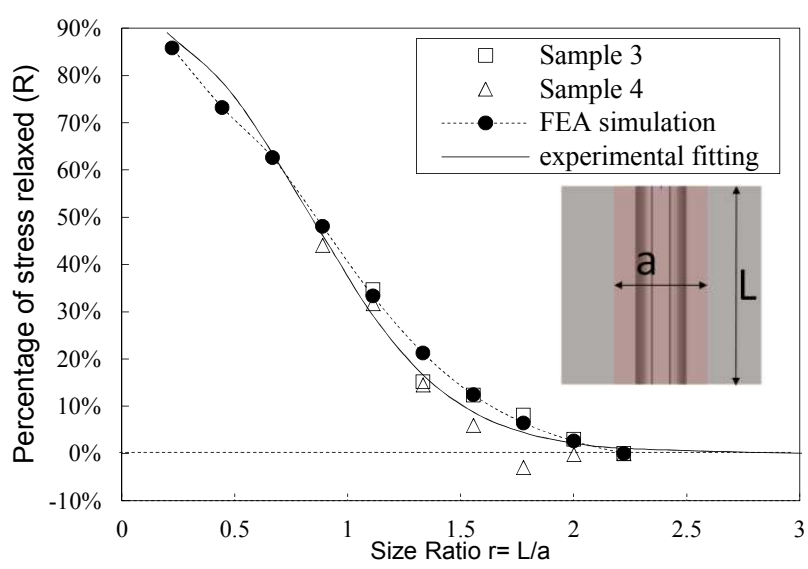

(b)

Figure 5. Relaxation of the highest residual stress. a) cut parallel to the weld, b) cut perpendicular across the weld.

The simulated residual stress field $\sigma_{\mathrm{x}}$ at the weld toe along path C-D when the sample size is reduced is predicted to change substantially as the sample size is reduced in length along this direction (Fig. 4b). This is confirmed by the measured values where a large amount of relaxation occurs, especially at the edges. The percentage relaxation of the highest residual stress $(R)$ for samples 3 and 4 is plotted in Fig. $5 \mathrm{~b}$ as a function of size ratio $r=L / a$, where $L$ is the length of the specimen and $a$ is still the size of HTZ. Curve fitting to the resultant plot gives the Eq. 2: 


$$
R=\frac{1}{1+\exp [3.3(r-0.8)]} \cdot 100 \%
$$

This produces the black solid line in Fig. 5b. This relationship has been observed and verified by another study [23] on AISI 1008 steel and two different welding geometries of ASTM A572 steel. It can be seen that the relaxation of the highest residual stress as measured in the center of the weld is relatively minor when $r>1.5$ and almost no relaxation occurs when the length of material along the welding direction is twice as long as the size of the HTZ $(r>2)$. Thus, one would predict that XRD experiments made from weldments can be expected to yield reasonable results as long as the dimensions of the welded pieces are not reduced below a value of $r>2$.

The welding residual stress is usually considered to be caused by the temperature and microstructural inhomogeneities produced during the welding process. The acquired data as compared to simulations suggests that the critical parameters in determining the extent to which a sample can be sectioned and still produce valid XRD data appear to be the length of material in relation to the size of the heat tint zone (HTZ) produced by the weldment even though heat affected zone (HAZ) is traditionally the most important microstructural feature associated with a change in material properties in welds. For the steel under consideration the presence of alloying additions of $\mathrm{V}$ and $\mathrm{Nb}$ cause the HAZ to be extremely small; however the presence of the HTZ shows that temperatures have still been significant outside the HAZ, as confirmed by the optical total strain measurement [24].

\section{Conclusions}

In summary, the purpose of this paper was to investigate residual stress relaxation behavior primarily of $\sigma_{\mathrm{x}}$, which is perpendicular to the welding direction, during consecutively reductions in specimen size of a simple T-weld. Finite-element simulation gives a good prediction of stress relaxation, matching well with the experimental results. When the materials were sectioned in the welding direction, only minor residual stress relaxation was observed as a function of size reduction as long as the cut is outside the heat tint zone and size ratio $t$ is greater than 0.3 . Relaxation is much more pronounced when sectioning perpendicular to the weld bead reduces length along the weld pass and a size factor $r$ was derived from the experimental data. If the size ratio $r$ is greater than 2 no relaxation should occur. If smaller than this value the relaxation of the highest residual stress can be approximated by the derived empirical relationship. For any size sample, measurements near the edges of the plate should be avoided where a large amount of stress relaxation is expected.

\section{Reference}

[1] S. Suresh: Failure of Materials, Cambridge University Press; $2^{\text {nd }}$ edition, November 28, 1998.

[2] J.Y. Yung and F.V. Lawrence: Analytical and Graphical Aids for the Fatigue Design of Weldments, Fatigue and Fracture of Engineering Materials and Structures, Vol. 8, No. 3, pp. 223-241, 1985.

[3] Yung, J.Y. and F.V. Lawrence: Estimating the Effects of Residual Stress on the Fatigue Life of Notched Components, University of Illinois, Materials Engineering Report No. 124, 1986.

[4] M. Chiarelli, A. Lanciotti and M. Sacchi: Fatigue resistance of MAG welded steel elements, International Journal of Fatigue, 21(10), 1099-1110, 1999. 
[5] G.A. Webster and A.N. Ezeilo: Residual stress distributions and their influence on fatigue lifetimes, International Journal of Fatigue, 23, suppl. 1, 375-383, 2001.

[6] J. Lu: Handbook of Measurement of Residual Stresses, Society For Experimental Mechanics, Lilburn, GA, 1996.

[7] N. Ganev, I. Kraus: On the application of X-ray tensometry to states of stress due to tangential machining of metal surfaces, Phys. Stat. Sol.(a), 106, 467-472, 1988.

[8] R.C. McClung: A literature survey on the stability and significance of residual stresses during fatigue, Fatigue Fract Engng Mater Struct 30, 173-205, 2007.

[9] Z. Qian, L.S. Chumbley, T. Karakulak, E. Johnson: The residual stress relaxation behavior of weldments during cyclic loading, Metallurgical and Materials Transactions A, Vol. 44, Issue 7, 3147-3156, 2013.

[10]M.T. Hutchings, P.J. Withers, T.M. Holden, T. Lorentzen: Introduction to the Characterization of Residual Stress by Neutron Diffraction, Taylor\& Francis Group, Boca Raton, FL, 2005.

[11]I.C. Noyan and J.B. Cohen: Residual Stress: Measurement by Diffraction and Interpretation, Springer-Verlag, New York, 1987.

[12]M.B. Prime: Cross-Sectional Mapping of Residual Stresses by Measuring the Surface Contour After a Cut, Transactions of the ASME, Vol. 123, April 2001.

[13]M.R. Hill: Modeling of Residual Stress Effects Using Eigenstrain, $10^{\text {th }}$ International Conference on Facture, Oahu, Hawaii, 2001.

[14]A.T. DeWald, M.R. Hill: Multi-Axial Contour Method for Mapping Residual Stresses in Continuously Processed Bodies, Experimental Mechanics 46: 473-490, 2006.

[15]C.D.M. Liljedahl, O. Zanellato, M.E. Fitzpatrick, J. Lin, L. Edwards: The effect of weld residual stresses and their re-distribution with crack growth during fatigue under constant amplitude loading, International Journal of Fatigue 32: 735-743, 2010.

[16]Y. Zhang, S. Ganguly, L. Edwards, M.E. Fitzpatrick: Cross-sectional mapping of residual stresses in a VPPA weld using the contour method, Acta Materialia, 52: 5225-5232, 2004.

[17]Z. Qian, L.S. Chumbley, E. Johnson: The effect of specimen dimension on residual stress relaxation of carburized and quenched steels, Materials Science and Engineering A, Vol. 529, 246-252, 2011.

[18]British Stainless Steel Association: Heat tint (temper) colours on stainless steel surfaces heated in air, www.bssa.org.uk.

[19]Baoping Bob He, Uwe Preckwinkel and Kingsley L. Smith: Fundamentals of Two-Dimensional X-ray Diffraction $\left(\mathrm{XRD}^{2}\right)$, CPDS-International Center for Diffraction Data 2000, Advances in X-ray Analysis, Vol. 43.

[20] ASTM E915, Standard Test Method for Verifying the Alignment of X-Ray Diffraction Instrumentation for Residual Stress Measurement, ASTM International, West Conshohocken, PA, 2004.

[21]Y. Ueda: Sectioning Methods, in 'Handbook of Measurement of Residual Stresses', Society For Experimental Mechanics, Lilburn, GA, 5-34, 1996.

[22] Ansys version 12.0, Ansys, Inc., Canonsburg, PA.

[23]Z. Qian, L.S. Chumbley, E. Johnson, work in progress.

[24]E. Johnson: Progress towards a model based approach to the robust design of welded structures, Ph.D Dissertation, 2013. 